\title{
Do que falam os turistas sobre o parque estadual lagoa da Jansen em São Luís/Maranhão no tripadvisor?
}

\section{What do the tourists speak about the Lagoa da Jansen state park in São Luís/Maranhão on tripadvisor?}

Saulo Ribeiro dos Santos

Coordenador do Observatório de Turismo do Maranhão e do curso de Turismo da Universidade Federal do Maranhão - UFMA, São Luís/MA, Brasil

E-mail: saulosantosma@uol.com.br

José Manoel Gonçalves Gândara

Professor do departamento de Turismo, do mestrado em Turismo e do doutorado de Geografia da Universidade Federal do Paraná - UFPR, Curitiba/PR, Brasil E-mail: jmggandara@yahoo.com.br 


\section{RESUMO}

A tecnologia tem favorecido a divulgação e promoção da imagem de destino turístico mediante sites específicos como os de compartilhamento de experiênciaturística. A exemplo, tem-se o TripAdvisor no qual é possível a inserção de comentários (positivos e negativos) acerca dos atrativos, empresas e serviços prestados no local visitado. Desta forma, objetiva-se no presente trabalho compreender a imagem percebida pelos turistas quanto a Lagoa da Jansen mediante análise de comentários no site TripAdvisor. A metodologia é considerada aplicada, descritivo-exploratório, de análisequalitativa. A amostra foi composta por quarenta e dois comentários dos turistas no site, quanto a "Lagoa da Jansen" na cidade de São Luís (Maranhão). A coleta de dados foi realizada nos meses de dezembro de 2015 a fevereiro de 2016. Analisou-se todos os comentários, utilizando o programaExcel para tabulação. Os principais resultados indicam que existe predominância de comentários negativos sobre a Lagoa da Jansen, mas que alguns positivos destacam aspectos quanto à paisagem,opção de lazer e entretenimento do lugar.

Palavras-chave:Tecnologia.Parque Estadual Lagoa da Jansen.Reputaçãoonline. São Luís.

\section{ABSTRACT}

Technology has favored the promotion of the image of a tourist destination, through specific tourism sites, such as TripAdvisor. For this is possible to insert comments (positive and negative) about the attractions, companies and services provided in the place visited. In this way, the aim of this work is to understand the image perceived by tourists about the Jansen Lagoon by analyzing comments on TripAdvisor. The methodology is considered applied, descriptive-exploratory, quantitative analysis. The sample was made up of forty-two comments from the tourists on the site, regarding the "Lagoa da Jansen" in the city of São Luís (Maranhão). Data collection was performed in the months of December 2015 to February 2016. All comments were analyzed using Excel for tabulation. The main results indicate that there is a predominance of negative comments about Jansen Lagoon, but that some positives highlight aspects of the landscape and leisure and entertainment options.

Keywords: Technology.Lagoa da Jansen State Park. Online Reputation. São Luís. 


\section{INTRODUÇÃO}

Vive-se numa sociedade cada vez mais fervorosa pelo consumo, e a atividade turística aparece como uma alternativa na comercialização de produtos, serviços, imagens, recursos e valores simbólicos (Gândara, 2008) que miram a satisfação das necessidades do homem, com o objetivo de atender anseios e expectativas dos turistas (Pinto, 2012).

Além disso, o turismo alia-se a tecnologia (Buhalis, 2000)com o objetivo de captar novos visitantes e investidores que possam promover o desenvolvimento do lugar, inovando, requalificando e promovendo singularidades da identidade local. A evolução do destino turístico quanto à imagem (Marujo, 2008) promovida pelos ganhos tecnológicos, criam diferenciais como a inclusão de produtos turísticos ou até mesmo uma nova forma de aproveitamento do atrativo, garantindo vantagem competitiva, o que pode tornar determinante na escolha do mesmo (Blanco, 2015).

A imagem do destino (Steinke, Reis Junior,\& Costa, 2014) forma-se pela captação e armazenagem dos locais visitados pelo turista (Gândara, 2008), portanto, a mesma deve chamar atenção pela qualidade dos atrativos, e, a tecnologia tem favorecido este aspecto quanto à avaliação, pois, os visitantes têm realizado comentários em diversas mídias sociais, e sites de compartilhamento de experiência direcionados ao turismo, como o Tripadvisor, em que é possível a realização de comentários tanto nos aspectos positivos e negativos,relacionados aos pontos turísticos, serviços, empreendimentos, entre outros(Law, Qi\&Buhalis, 2010; Liu, 2000;Montardo, 2009; Tripadvisor, 2013).

O conteúdo gerado nas avaliações de desempenho pelos usuários na internet tem contribuído para uma nova visão quanto ao destino ou produto turístico (Gândara, Fraiz,\&Manosso, 2013). Além disso, o usuário tem criado uma rede de avaliação que permite o aumento do fluxo de informações sobre determinado serviço ou produto, facilitando a comunicação e análise(Reino, Lamsfus,\&Azua-Sorzabal, 2012) por todos que possuem acesso à internet.

Por outro lado, o comportamento do consumidor modifica-se com a tecnologia (Baggio \&Del Chiappa, 2014; Buhalis, 2000) mediante a interação com fornecedores que passam a utilizar a internet como forma de propagação dos produtos e serviços turísticos. Portanto, compreender a visão e experiência do turista/usuário através de sites turísticos, caracteriza-se como uma opção de entender o que pode ser aperfeiçoado, melhorado e modificado (Solomon, 2011).

A capital do estado do Maranhão, São Luís, diferencia-se quanto aos demais destinos turísticos brasileiros, pois, o seu produto turístico não está concentrado somente no 
segmento cultural, mas também no de natureza, com espaços na urbe, como o caso de parques urbanos que são utilizados como local para visitação (Santos et al., 2013). Em meados de 2001, São Luís presenciou a urbanização do entorno da Unidade de Conservação Estadual Parque Ecológico da Lagoa da Jansen que promoveu benfeitorias ao local, criando ambientes de lazer e entretenimento para a população e visitantes (Coelho, 2002).

Mediante tal justificativa, questiona-se: qual a percepçãodos turistas sobre o parque estadual Lagoa da Jansen em São Luís? Neste segmento, surge este trabalho de investigação com o objetivo de compreender a percepção dos turistas quanto à Lagoa da Jansen mediante análise doscomentários contidos no site Tripadvisor. Para alcance do objetivo, utilizou-se dos seguintes procedimentos metodológicos: levantamento do estado da arte sobre imagem, percepção e tecnologia; caracterização sobre Parque Estadual Lagoa da Jansen; reputação onlinecom base nos comentários no site Tripadvisorentre os meses de dezembro de 2015 a fevereiro de 2016.

$\mathrm{O}$ artigo está divididoinicialmente pelaintrodução, no qual aborda-se aspectos quanto a justificativa e o objetivo, em seguida tem-se a metodologia, no qual traz-se questões sobre os métodos e técnicas utilizados. Após, faz-se uma descrição do parque urbano Lagoa da Jansen. Depois, analisa-se os comentários dos usuários do site Tripadvisor, e por fim são apresentadasas considerações finais.

\section{PROCEDIMENTOS METODOLÓGICOS}

A pesquisa caracteriza-se como descritiva e exploratória, sendo que a descritiva tem por fim criar meios para descobrir e observar fenômenos, de forma a classificá-los, descrevê-los e interpretá-los para então estabelecer relações entre as variáveis de estudo. E exploratório, no sentido de levantar dados que servirão de apoio para futuras pesquisas (Cervo \&Bervian, 2004).

Classifica-se como bibliográfica, pois, “procura explicar um problema a partir de referências teóricas publicadas em documentos" (Cervo \&Bervian, 2004, p. 55). Além disso, buscou-se como fonte as bases de dados -Redalyc, Portal de Periódicos CAPES e Publicações em Turismo -, utilizando palavras chaves como:imagem turística, parques urbanos e reputação online.

Classifica-se também como documental,que refere-se à análise de materiais que ainda não receberam um tratamento analítico e que podem ser reelaborados, como esclarece Creswell (2007, p. 192): “documento públicos, como atas e reuniões e jornais; documentos privados, como registros, diários e cartas e discussões via e-mail”. 
Quanto aos fins,caracteriza-se como quantitativa (perfil dos usuários) etratousequalitativamente os comentários online dos usuários (turistas) quanto à percepção dos mesmos sobre o produto turístico de São Luís, o Parque Estadual da Lagoa da Jansen.

Utilizou-se para tratamento de dados a netnografia que de acordo com Hine (2000), Kozinets (1998) e Pereira (2005) é uma forma intensa de participação não obstrutiva e observacional, pois, a criação dos dados online é realizada de forma textual. E, portanto, os métodos qualitativos empregados em pesquisas relacionadas ao comportamento do consumidor virtual auxiliam na exploração das relações existentes entre afirmativas previsíveis das novas tecnologias.

Ou seja, a reputação online tem como objetivo compreender a conversação de usuários em espaços administrados por uma empresa que dão voz ao consumidor (Montardo, 2009), e também éuma questão de monitoramento de mídias sociais que tem crescido com o interesse deacompanhar tais ferramentas como forma de estudo para compreenderas métricas válidas (Cerqueira \& Silva, 2011). No turismo, o uso da reputação online tem-se tornado frequente, principalmente com o advento dos sites turísticos que congregam espaços para a inserção de comentários dos viajantes e usuários sobre os produtos e serviços, ou até mesmo da infraestrutura do destino.

No turismo há estudos nacionais e internacionais que utilizam tal metodologia como forma de avaliar empreendimentos e destinos turísticos quanto aos depoimentos para melhor conhecer/compreender a percepção dos usuários sobre os CGU (Corrêa \& Hansen, 2014; Limberger etal., 2014; Mendes Filho \& Carvalho, 2014).

Justifica-se também o uso da reputação online, pois,

A coleta de dados na internet é justificada porque no turismo os depoimentos dos usuários sobre suas experiências inseridos na rede tiveram muita aceitação por parte dos consumidores, tornando-se cada vez mais comum a utilização dos sites de troca de informações especializados, blogs ou redes sociais para mensurar estas experiências de usuários de equipamentos turísticos, como meios de hospedagem, restaurantes e também dos atrativos (Feger\& Souza Júnior \&Gândara, 2016, p. 145).

Além disso, a reputação online ganhou importância pela confiabilidade que os consumidores possuem nas fontes de informação, influenciando diretamente outros consumidores (Friedlander, 2012; Gândara,FraizBrea,\&Manosso, 2013).

A reputação online atua como um estímulo à percepção cognitiva da qualidade gerando confiança, do mesmo que pode serum indicador de confiabilidade. Além disso, nesta perspectiva a reputação online serve como um meio de reduzir a incerteza e gerar uma sensação de confiança entre os consumidores para atrair mais transações para as empresas (Baggio \& Del Chiappa, 2014). 
Como a pesquisa trata da percepção dos usuários, Barich e Kotler (1991) e Mason (1993) acreditam que a reputação concebe uma dimensão da imagem. Já para Chun(2005), a imagem é parte integrada da reputação, correspondendo à percepção e perspectiva dos stakeholders internos e externos. A pesquisa em sites de depoimentos onlineé importante para compreender e analisar as informações e dados postados na mídia social com o objetivo de melhorar os serviços (Gândara,FraizBrea,\&Manosso, 2013).

Como base para coleta de dados (comentários),justifica-se a escolha do site Tripadvisor $^{l}$ por ser um dos principais portais especializados em turismo em termos de conteúdo gerado pelos usuários, com projeção internacional e forte cooperação e contribuição de participantes, além de ser referência em consulta no momento da tomada de decisão final sobre um determinado destino e/ou empreendimento turístico, além de ter sido utilizado por Beal e Strauss (2008) e María-Dolores \& García \&Mellina (2012) como coleta de comentários com fins de análise reputação online quanto a equipamentos turísticos.

O conjunto de opiniões que se realiza na internet sobre uma determinada marca, bem ou serviço, é o que constitui a 'reputação online' de uma empresa. A princípio, tratase de algo que está fora do alcance do empresário, já que se supõe que todas as opiniões são emitidas por usuários independentes [...] é importante compreender também em que medida os internautas recorrem às opiniões de outros usuários para tomar uma decisão de compra² (María-Dolores, García,\&Mellina, 2012, p. 03, tradução nossa).

Do início dos comentários até o dia 25 de janeiro de 2016 existiam 900 comentários sobre a Lagoa da Jansen em São Luís (Tripadvisor, 2016). Sendo que fez-se um recorte quanto a sazonalidade turística (alta temporada em São Luís) coletando os comentários compreendidos entre os meses de dezembro de 2015 a fevereiro de 2016, no qual obteve-se 42 comentários, sendo estes inseridos numa planilha do Excel, os quais foram lidos e separados durante 1 mês conforme categorização definida por GoPaul (2014) em positivo e negativo.

Dentre os 42 comentários pesquisados (Tripadvisor, 2016) descartou-se 4, por serem de origem local, ou seja, da cidade de São Luís, sendo que a pesquisa delimitou-se em compreender a visão dos turistas e não dos moradores. Portanto, para análise considerou-se somente 38 comentários. Na planilha do Excel separou-se por colunas utilizando os

\footnotetext{
${ }^{1}$ Dados de 2012 apontam que o TripAdvisor é o maior site de viagens do mundo, com um cadastro de milhões de usuários/viajantes que buscam informação sobre lugares com o objetivo planejar uma viagem (Tripadvisor, 2013).

${ }^{2}$ El conjunto de opiniones que se realizan en Internet, sobre una marca, bien o servicio, es lo que constituye la 'reputación online' de una empresa. En principio, se trata de algo que queda fuera del alcance del empresario, ya que se supone que todas esas opiniones son vertidas por usuarios independientes.[...] También resulta interesante saber, en qué medida los internautas recurren a las opiniones de otros usuarios para tomar una decisión de compra.
} 
parâmetros definidos por Quiroga, Mondo e Castro Júnior (2014) que são: local de origem (cidade ou país do usuário), título do comentário (título que o usuário utilizou), comentário (comentário do usuário), data (dia, mês e ano dos comentários, sendo que nem todos possuem data completa), nível do colaborador (classificação do site para os usuários que comentam),número de estrelas (classificação utilizada para o atrativo quanto à significância) e via app do celular (comentário realizado no aplicativo do celular). Após o levantamento do perfil tinha-se mais duas colunas, sendo uma com os comentários na íntegra e outra onde classificou-se em positivo e/ou negativo conforme orientações de GoPaul (2014). Para compreensão e análise dos comentários segue-se orientações de Minayo (2008) que adverte quanto ao rigor metodológico na condução de pesquisas qualitativas, ressaltando a importância de se ter proposições que auxiliem na transformação da realidade.

Assim, os comentários foram analisados conforme orientações de Figueiredo , Chiarie Goulart (2013, pp. 130-131) sobre discurso do sujeito coletivo que é:

[...] uma técnica de tabulação e organização de dadosqualitativos [...]permite que se conheça ospensamentos, representações, crenças e valoresde uma coletividade sobre um determinado temautilizando-se de métodos científicos. [...] O Discurso do Sujeito Coletivo é uma proposta de reconstituição de um ser empírico coletivo, opinante na forma de um sujeito de discurso emitido na primeira pessoa do singular. O social falando na primeira pessoa do singular é o regime natural de funcionamento das opiniões ou representações sociais.

O discurso do sujeito coletivo é um meio para analisar os comentários online, pois, este método auxilia na análise do conjunto de falas expostas no TripAdvisor, contribuindo para analisar depoimentos e demais materiais verbais que fazem parte do corpus, do qual extrai-se as principais ideias centrais ou expressões (Chun, 2005; Gretzel\&Yoo, 2008).

\section{REPUTAÇÃO ONLINE: ANÁLISE DOS TURISTAS SOBRE O PARQUE URBANO LAGOA DA JANSEN}

A Lagoa da Jansen possui uma extensão de 150hectares, com profundidade média de 3,5 metros, localizada no município de São Luís (capital do estado do Maranhão) na área noroeste da ilha, sendo delimitada ao norte com a praia da Ponta D'areia e bairro da Ponta do Farol, ao sul com o bairro do São Francisco, a oeste com o bairro da Ponta D'areia e a leste com os bairros do Renascença I e II (Figura 1) (Coelho, 2002). 


\section{Figura 1 - Mapa de localização da Lagoa da Jansen no Brasil e em São Luís}

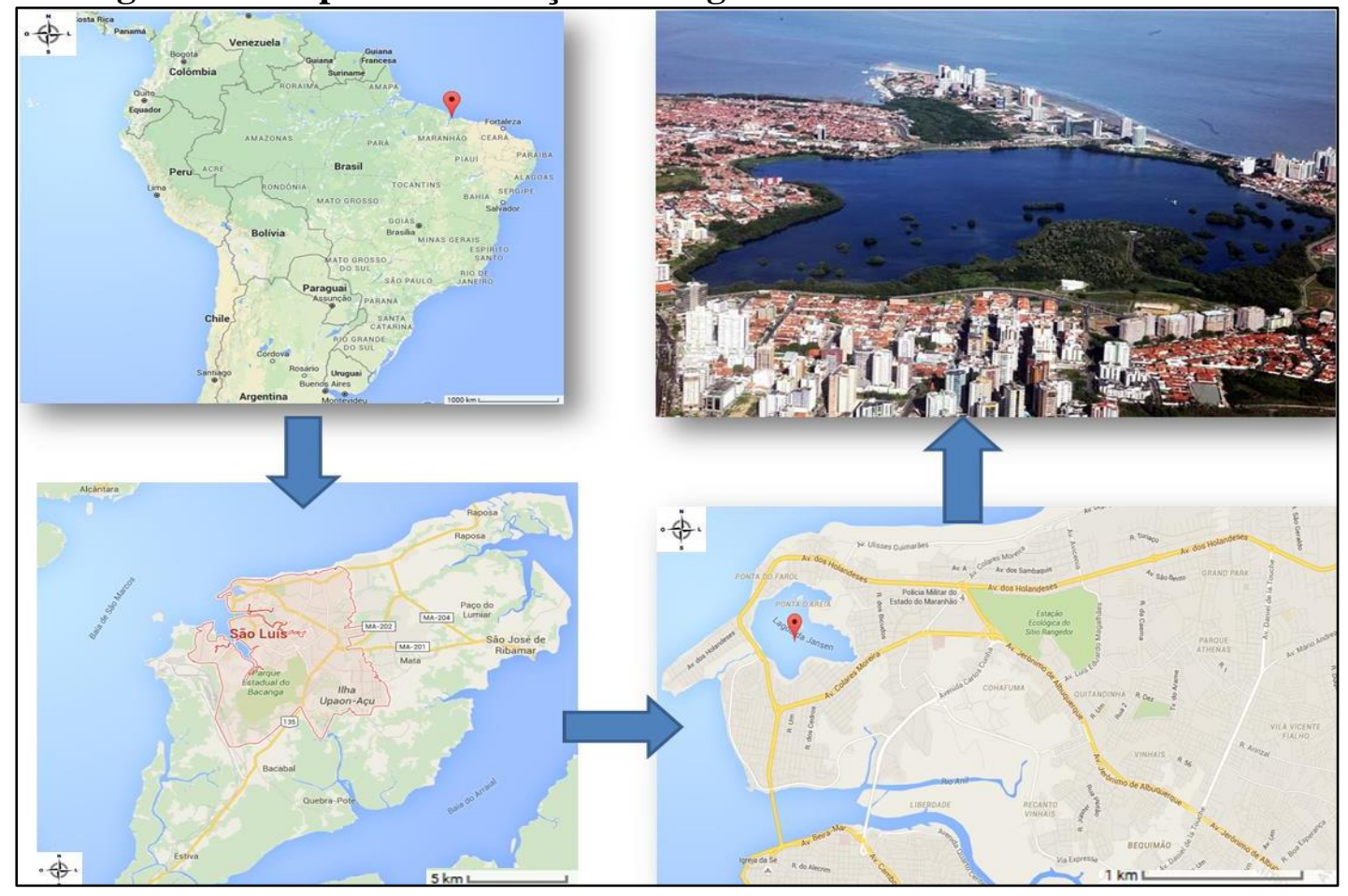

Fonte: Adaptado de Google Maps (2016) e Soares (2012).

São Luís vivenciou na década de 70 a implantação de um complexo siderúrgico com o objetivo de escoar o minério da Serra dos Carajás (Pará) pelo porto, o que gerou a criação de loteamentos com fins habitacionais em diversos locais da cidade, promovendo umaocupação desenfreada (migração de pessoas do interior e estados vizinhos em busca de emprego) em áreas de mangues e alagadiças, criando uma desordem na estrutura urbana de São Luís (Coelho, 2002). Em 1974, o Plano de Urbanização do bairro da Ponta D'areia foi elaborado com o objetivo de transformar o local em um polo turístico e residencial de classe alta, pela proximidade com a praia e o centro da cidade. A Lagoa da Jansen por estar na área do entorno da Ponta D'areia sofreu diversas invasões e investimentos imobiliários formando um contraste na paisagem (Coelho, 2002).

\footnotetext{
Na década de 1970, o aterramento para a ligação dos bairros São Francisco e Ponta D’Areia destruiu o igarapé da Jansen, facilitando, assim, o acesso às praias. Deste aterramento, formou-se a Laguna da Jansen, que, em 2001, recebeu obras de infraestrutura para o lazer e turismo [...]. Com recursos do Ministério do Meio Ambiente, o Governo do Maranhão realizou melhorias na Laguna, principalmente voltadas à despoluição e ao agenciamento de calçadão pontuado por equipamentos esportivos e de lazer (Santos et al., 2013, p. 05).
}

De acordo com a Lei 4.870 (1988) 23 de junho de 1988,a Lagoa da Jansen foi transformada em parque ecológico mediante seu valor estético e paisagístico, além da fauna e flora.Mesmo com a proteção legal, a área continuou sendo foco de especulação imobiliária e invasões acarretando problemas ambientais à localidade (Santoset al., 2013). "Assim, desde a 
sua construção, o parque foi tido como um local turístico referenciado pela sua beleza ambiental, a pesca artesanal e lazer" (Masulloetal., 2014, p. 01).

Mediante tais aspectos históricos, geográficos e turísticos, identifica-se a relevância da Lagoa da Jansenenquanto produto turístico de São Luís. Desta forma, este território passou a incorporar no TripAdvisor uma aba específica no item "o que fazer", sendo recomendado pelos usuários e turistas. Ou seja, conforme María-Dolores, García eMellinas (2012) qualquer turista pode escrever sobre um serviço, produto e sua experiência e é fundamental destacar as opiniões, pois, são relevantes, além do nível de veracidade destas.

Compreendendo tal aspecto, esta pesquisa se propõe a levantar e analisar as percepções dos usuários quanto aos comentários postados no TripAdvisor sobre a Lagoa da Janen. Desta forma, tem-se inicialmente o perfil dos mesmos de acordo com os parâmetros de Quiroga, Mondo e Castro Júnior (2014), a saber: quanto à origem tem-se que

$10 \%$ são de Brasília, $8 \%$ da Bahia, 5\% do Ceará e variando entre 2\% e 3\% de outros estados da federação.Em análise aos dados da Secretaria Municipal de Turismo de São Luís (São Luís, 2014), o perfil dos visitantes de São Luís quanto à origem são oriundos de Brasília (4,64\%), 2,82\% da Bahia e 6,45\% do Ceará, percebe-se semelhança quanto à procedência dos turistas que visitaram São Luís no período.

Quanto ao gênero dos usuários, 61\% são do sexo masculino e 39\% feminino, sendo o mesmo resultado da pesquisa da Secretaria Municipal de Turismo de São Luís realizada em 2015, no período junino (São Luís, 2014).

O mês commaior número decomentários foi janeiro, com 52\%, seguido de dezembro com $46 \%$, e fevereiro com $2 \%$.Justifica-se a concentração de comentários nos meses de dezembro e janeiro em decorrência destes serem classificados pela Secretaria Municipal de Turismo de São Luís como período de alta temporada em São Luís, e também, no mês de janeiro estes realizam a pesquisa de demanda da alta temporada para levantar o perfil dos visitantes e suas impressões sobre a cidade (São Luís, 2014).

Seguindo os parâmetros de Quiroga, Mondo e Castro Júnior (2014), quanto ao nível do colaborador, o TripAdvisor classifica-os entre 1 e 6. Quanto maior a numeração, maior é o valor que este usuário possui em relação ao número de postagens e contribuições realizadas no site (TripAdvisor, 2013). Na presente pesquisa, a maior parte dos usuários estão classificados no nível 3 (32\%), seguidos dos que estão pontuados com 5 (29\%) e 14\% os de nível 4.

Os colaboradores de nível 3, 5 e 4 foram os que mais comentaram, e, portanto, torna-se confiável a opinião destes para o leitor, pois, esta classificação do TripAdvisor para o comentarista representa confiabilidade de acordo com Filieri(2015).Para IvarsBaidalet al. 
(2014) a internet tem sido utilizada como um meio para obter informações sobre o destino e em São Luís, cerca de 0,20\% apontaram que a internet foi um veículo que influenciou na escolha da mesma como opção, frente a outros destinos consolidados (São Luís, 2014). Porém, pesquisa do TripAdvisor (2013) aponta que 3 em cada 5 viajantes online do mundo utilizam o site TripAdvisor para consulta, e que 33\% das pessoas buscam informações em sites turísticos, 24\% dos viajantes utilizam o TripAdvisor como fonte de dados para elaboração da viagem, e $21 \%$ compram ou fazem algum tipo de transação online relacionado a viagem. Outra pesquisa desenvolvida por Funsherpa (2018) destaca que 85\% dos viajantes a lazer no mundo utilizam o smartphone durante a viagem e $87 \%$ dos americanos que viajam utilizam a internet para pesquisar ou comprar algo relacionado à viagem. Assim, compreendese que:

O viajante de hoje tem um apetite voraz por todo e qualquer tipo de informação tradicional e online, com o objetivo de planejar sua viagem antes e durante. $\mathrm{O}$ aumento do uso da informação virtual é também um fenômeno que transcende os viajantes de todas as idades e níveis de afluência (Brown, 2015, p. 23, tradução nossa).

Em relação à classificação do atrativo Lagoa da Jansen a maioria (31\%) opinou como 3 estrelas, seguidos de 2 estrelas com $29 \%$ e $21 \%$ com 4 estrelas. Ou seja, a Lagoa da Jasen possui boa avaliação e indicação pelos usuários como local de visitação em São Luís, ratificado pelo documento oficial do turismo do estado do Maranhão, Plano Maior 2020 que classifica a Lagoa da Jansen como recurso de alta prioridade do polo turístico São Luís, o que equivale ao conceito de 4 e 5 estrelas. Neste documento, os recursos de alta prioridade são aqueles que possuem valores potenciais mais elevados e que necessitam de investimentos em infraestrutura e comunicação e que poderão gerar receitas importantes advindas do turismoquando este bem planejado e organizado, contribuindo assim para a consolidação da imagem turística do estado do Maranhão (Maranhão, 2012).

Quanto àqueles que avaliaram o atrativo pelo aplicativo do TripAdvisor para celular foram $50 \%$, assim como pelo site da organização. Já se percebe a importância deste instrumento tecnológico como um facilitador para que turistas possam postar seus comentários no momento em que vivenciam as experiências (Blanco, 2015; Segittur, 2013; 2015). Autores como Main (2001) e Pechlaneretal. (2002) afirmam que a rápida transmissão de dados pela internet tem reduzido o tempo de resposta e que isto influencia positivamente na satisfação do cliente, pois o comportamento de resposta se converteu em um fator essencial para o êxito de organizações turísticas. Pesquisas da Funsherpa (2018) destacam que 30\% dos viajantes utilizaram aplicativos móveis para fazer reserva em hotel e $29 \%$ para encontrar voos, portanto, há uma tendência crescente de usuários que se conectam através da internet em sites e aplicativos de turismo para realizar diversas atividades relacionadas à viagem. 
Com relação ao título que os usuários destacaramnos comentários cerca de $60 \%$ foram negativos, enfatizando principalmente o aspecto da poluição e sujeira encontradas no local, como por exemplo: "Poluída e perigosa"; "Lagoa abandonada"; "Lixo"; "Lagoa aos pedaços"; "Péssimo"; "Sujeira a céu aberto", entre outros. Títulos como estes remetem a imagem que os usuários possuem sobre o produto visitado, e o conteúdo gerado contribui na avaliação do desempenho do atrativo turístico, pois, de acordo com Quiroga, Mondo e Castro Júnior (2014, pp. 98-99):

A internet representa hoje uma das principais ferramentas de pesquisa de mercado que os consumidores utilizam. Dentro do contexto turístico, por ser um serviço, os aspectos tangíveis (fotos, indicação de estruturas e outros) são ponto fundamental na análise e escolha do que consumir. Outro ponto relevante, com grande aceitação no mercado, foram osdepoimentos (positivos e negativos) que turistas inserem na internet sobre sua experiência em determinada viagem ou hotel.

A imagem do destino turístico é reconhecida por afetar na percepção do usuário na escolha do destino a ser visitado (Añaña, Anjos,\& Pereira, 2016) e atualmente, com a alta competitividade do mercado turístico, os consumidores estão cada vez mais informados, e portanto, os destinos turísticos devem adotar estratégias adequadas e monitorar os conteúdos online para diferenciar-se dos demais, projetando uma imagem singular e positiva na mente dos consumidores.

Em reportagem publicada pelo portal Imirante (2014,) é destacado o aspecto da poluição como um causador de mau cheiro e reclamações dos frequentadores do parque estadual. Pois,

[...] o acúmulo de sedimentos e de restos de matéria orgânica às margens da Lagoa da Jansen, em São Luís, está sendo responsável por um intenso mau cheiro no local. As pessoas que transitam pela área reclamam do odor proveniente da água contaminada, que se intensifica ainda mais por causa da falta de tratamento adequado para os dejetos.

Um destino turístico, como São Luís, deve ter ambientes estruturados e limpos para promover uma experiência positiva aos visitantes (Murphy, Pritchard,\& Smith, 2000), pois, a experiência do turista na destinação está interligada aos atrativos (artificiais, culturais e naturais) que compõem o cenário turístico. A construção da imagem do destino é perceptual e interpretada subjetivamente pelo turista, que "de acordo com seu itinerário de viagem, bagagem cultural, propósito da visita, nível educacional e experiências passadas" (Añaña, Anjos,\& Pereira, 2016, p. 311) podem ser positivas ou negativas. Portanto, comentários positivos possuem impacto positivo e os negativos idem, o que influencia diretamente na escolha do destino por parte do consumidor (Buhalis, 2000).

Os problemas mencionados nos títulos são visíveis também pela população como destacado na reportagem. Ou seja, aspectos de infraestrutura sanitária prejudicam não somente a fauna e a flora, além da paisagem natural do parque ecológico, mas também 
compromete a imagem do destino turístico (Chagas \& Dantas, 2008).Por outro lado, Santos etal. (2013, p. 08) afirmam que "fica claro, portanto, que um atrativo paisagístico natural, como no caso da laguna, se bem planejado e organizado, pode promover melhorias para determinado setor urbanístico" e turístico, que Sakata (2011, p. 32) corrobora, esclarecendo que:

\begin{abstract}
A paisagem da lagoa não era valorizada tanto que os empreendimentos construídos antes da obra de urbanização voltaram suas janelas nobres para o mar [...]. Após a implantação do projeto Lagoa da Jansen, as vistas para a lagoa [...] passaram a ser consideradas vistas privilegiadas.
\end{abstract}

Ou seja, a paisagem natural da Lagoa da Jansen não é um atrativo somente turístico, mas imobiliário que contribui para a expansão urbana no território do entorno da mesma. Em pesquisa de Santos et al. (2013, p. 08) destacam que:

\begin{abstract}
Gradativamente, a paisagem urbana vai se modificando [...] com a urbanização da laguna. Os moradores perceberam aspectos positivos das melhorias estruturais realizadas na região, bem como suas consequências favoráveis [...]. A evidencia que não só o bairro do Renascença II, mas, de maneira geral, todos os situados nas proximidades da laguna sofreram alterações na paisagem urbana. Ou seja, as intervenções urbanísticas constituíram - e ainda constituem - fatores que impulsionam a transformação paisagística [e turística] do local.
\end{abstract}

Na figura 2 é possível perceber a verticalização no entorno da Lagoa da Jansen, mediante especulação imobiliária, assim como, adensamento de construções com fins de moradia e comercial, criando um espaço de entretenimento e lazer para residentes e visitantes.

Figura 2 - Verticalização no entorno da Laguna da Jansen em São Luís

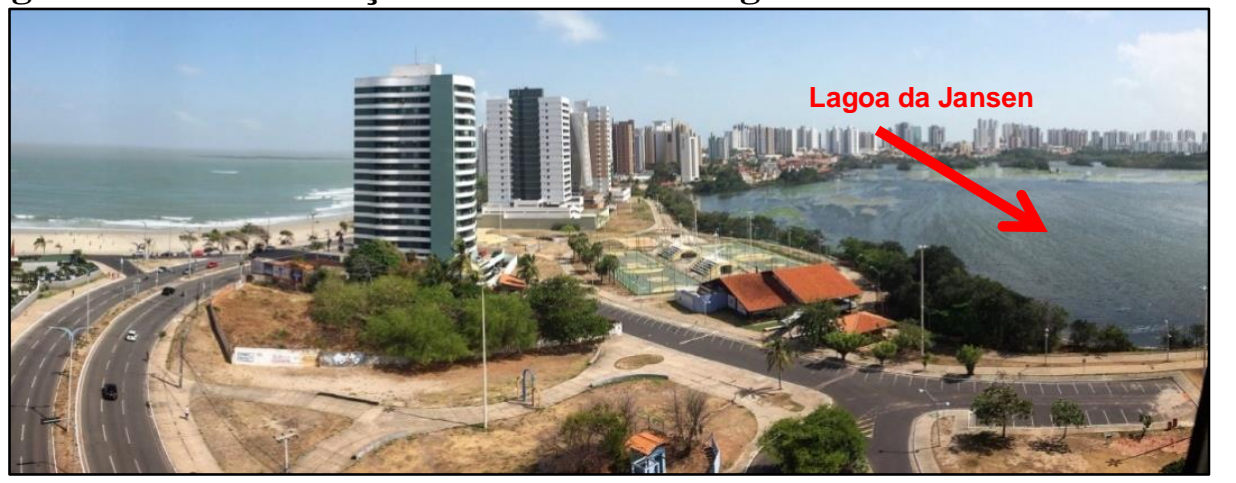

Fonte: Santos (2016)

A comunidade local utiliza os equipamentos urbanos da Lagoa da Jansen para a prática do esporte e lazer, pois, "trata-se de uma área protegida estadual cujos objetivos originaisrelacionam-se ao 'uso público, diversões, esportes e áreas verdes dentro doslimites a serem fixados pelo Poder Público"” (Maranhão, 2012).

A maior concentração de infraestrutura urbana no entorno da Laguna da Jansen encontra-se em área correspondente aos bairros Renascença II e Ponta do Farol, com equipamentos para lazer, bares, restaurantes, quadras de tênis, pista de skate, quiosques, pista de ciclismo, concha acústica e mirante. (Santos et al., 2013, p. 06). 
Outro termo destacado nos títulos foi abandono em decorrênciado estado atual que se encontra o parque ecológico Lagoa da Jansen que para Teixeira (2016), professor da Universidade Federal do Maranhão é de destruição e insegurança.

Quebraram tudo, roubaram o que havia lá dentro. Alguns até chegam a brigar por aqui por perto. 'O movimento caiu e a maioria dos turistas que passa por aqui reclama desse abandono', afirmou o vendedor Raimundo Lima Soares, que paga R\$ 60 por mês para ter o direito de utilizar um quiosque bem próximo ao antigo posto (G1 MA, 2012).

O destino turístico é um local que as pessoas viajam para conhecer, desbravar e se encantar, além de satisfazer as necessidades e desejos, por isto, devem promover satisfação física, psicológica e intelectual de forma que a experiência turística e o consumo atendam às exigências de forma qualitativa (Pike, 2008). Assim, torna-se fundamental que o produto turístico esteja organizado com facilidades e serviços oferecidos, acessibilidade, infraestrutura, imagens e preços conforme destacam Middleton e Clark (2012).

Com o objetivo de reforçar a segurança pública da região da Lagoa da Jansen, em dezembro de 2015, o atual governador do estado do Maranhão entregou à cidade de São Luís “o novo prédio da Companhia de Polícia de Turismo Independente (CPTur) na Lagoa da Jansen. O equipamento fortalece as ações de segurança para moradores e turistas da região da Ponta do Farol, Ilhinha, Ponta d'Areia e São Francisco" (Maranhão, 2015).

[...] 'Contamos com um contingente de 175 oficiais que se revezam entre os plantões e realizam policiamento ostensivo. Os grupos de oficiais fazem rondas a pé e em patrulhas motorizadas que contam com viaturas, motos e quadrículos' [...]. Ele ressaltou que os oficiais tem o domínio de mais de um idioma, o que permite orientar grupos de estrangeiros que visitam os locais, transmitindo segurança e cordialidade. [...] 'Nós somos aliados da população. O policial precisa deixar de ser visto como aquele indivíduo que só serve para momentos de nervosismo e passar a ser o colaborador da paz, ser visto como ser humano que entende e ajuda os cidadãos. Nosso papel é proteger e colaborar para que muitos turistas queiram retornar a nossa cidade' (O Itaqui, 2016).

O investimento em policiamento é fundamental para a atividade turística, pois, a segurança é um dos principais itens apontados pelos turistas quanto à escolha do destino conforme afirmamKurež e Prevolšek (2015), já que a segurança impacta diretamente nos mais diversos segmentos relacionados direta e indiretamente à atividade turística, e este efeito pode ser grande ou pequeno, de acordo com a dependência turística que o destino possui.

Teve-se também menções positivas nos títulos como: "Agradável”; "Lindo local"; Recomendo"; "Paisagem bonita"; que remetem a boa imagem que a paisagem natural contrasta com a urbe.E outros, destacaram a vida noturna e gastronômica do local, com títulos como: "Vá a noite"; “Agitado"; "Ótimo bares"; "Bares"; "Badalação maranhense”.

Ter uma imagem positiva é essencial para que o destino turístico esteja na mente do consumidor, além disso, tornou-se objeto de estudo de pesquisadores como Tasci eGartner 
(2007), Prayag (2008) e Nghiêm-Phú (2014) por a imagem ser um dos principais fatores de decisão na escolha do destino, assim como a reputação onlineque de acordo com Del Fresno (2012) é o resultado do que consumidores, ex consumidores, futuros consumidores escrevem e transmitem a outras pessoas por meio da internet em sites e redes sociais quanto suas percepções e experiência.

Estudos de GoPaul (2014) indicam quanto aos diferentes elementos de interesse como a importância dos comentários, se são positivos ou negativos, conforme segue abaixo:

a) Positivos:

A vista da Lagoa do Jansen é bem interessante, consegue-se ver algumas embarcações trafegando na lagoa;

Bom lugar com bares e casas noturnas. Com boas opções de restaurantes. Ambiente relativamente seguro durante a noite é próximo a diversos hotéis;

Bom o local precisa de algumas melhorias, porem é um lugar bonito, mas precisa ser restaurado muitas coisas;

Este ambiente é de muita beleza natural. O demérito está na estrutura construída: feia, sem um conceito arquitetônico;

Possui bares e restaurantes excelentes durante a noite boates aluguel de patins e charrete;

Tive o prazer de me hospedar em frente dessa área de preservação ambiental. Possui duas pistas, uma para bicicletas e outras para corrida/caminhada com extensão de $5 \mathrm{~km}$. Ainda tem barracas de água de coco em alguns locais;

Lagoa apresenta um traço marcante na paisagem de São Luís. Ao lado do mar e dos rios que cortam a cidade dá um tom especial a geografia da cidade. Apesar de sofrer com a disposição de esgoto, comum na maioria dos corpos d'água das cidades brasileiras, mesmo assim é um lugar bonito para se contemplar;

A grande concentração de bares e restaurantes tornam a região um prato cheio pros que gostam de uma noite agitada. Tem opções pra todos os gostos.

Nos comentários sãodestacadas a paisagem natural, o entretenimento e a vida gastronômica do local. Pois, por tratar-se de um local turístico de São Luís, concentra diversos empreendimentos que ofertam serviços no segmento da alimentação e lazer como bares e restaurantes.

A Lagoa da Jansen se encontra em uma região urbanizada, totalmente habitada em seu perímetro marginal, rodeada por pavimentação decalçadas, ciclovias e estradas asfaltadas. Em seu entorno encontram-semoradias em forma de casa e edifícios, além de prédios comerciais, bares erestaurantes (Maranhão, 2012, p. 07).

Em pesquisa realizada por Santos et al. com moradores de um dos bairros que circundam a lagoa, evidenciaram também aspectos quanto ao lazer e entretenimento na região.

A grande maioria dos entrevistados afirmou que as opções de entretenimento (31\%) foram os itens que mais mudaram no bairro. [...] Outras alternativas de lazer (12\%) aparecem em terceiro lugar, devido também à oferta de equipamentos para essa finalidade na região da laguna, principalmente na parte do Renascença II, como pista de skate, equipamentos de musculação, concha acústica e praça. (Santos et al., 2013, p. 10)

Da relação da paisagem com o turismo entende-se que este é um vetor de desenvolvimento da atividade (Santos, 2015), pois, trata de um atrativo que o turista muitas 
vezes busca, seja no âmbito natural ou urbano, além de ser diretamente influenciada pelas ações antrópicas no decorrer das incorporações estratégicas promovidas pelas políticas públicas (Santos et al., 2013).

Na visão de Yázigi (2002), a paisagem é objeto de interesse dos moradores, mas também dos turistas por possuir significados, símbolos, que estimula e desperta a atenção "pela diferença do cotidiano ao qual pertencem, desempenhando várias funções: espaço mediador da vida em sociedade, referencial (geográfica, psicológica, entre outras), fonte de contemplação e inspiração, etc." (Dal Molin \& Oliveira, 2008, p. 08).

No documento oficial do turismo maranhense (Plano Maior 2020) a Lagoa da Jansen está classificada como um recurso de alta prioridade, que são aqueles que possuem valores potenciais elevados e que precisam de alguns investimentos em desenvolvimento e comunicação e que podem gerar receitas por meio da atividade turística, quando devidamente organizados, contribuindo desta forma, com a consolidação da imagem e posicionamento do Maranhão no mercado turístico (Maranhão, 2012).

Quanto aos comentários negativos, tem-se:

A Lagoa é poluída, com pouquíssimas pessoas caminhando, clima de insegurança e nada interessante para fazer;

Não só a lagoa, mas a maioria dos pontos turísticos de São Luís estão largados. Sem conservação, esperava um local agradável com locais para sentar e relaxar. Quem percorre o perímetro da lagoa encontra até porcos soltos. Decepção;

$\mathrm{Na}$ internet vi que a lagoa de Jansen era um lugar turístico, dessa forma resolvi ir até o local ver. A visita foi frustrante, pois é uma lagoa que tinha tudo para ser um dos melhores lugares da cidade, mas ao invés disso acumula muito sujeira, lodo, brinquedos abandonados da mesma forma que a lagoa cheia de esgoto abandonada. O que salva são o restaurantes e bares das imediações da lagoa;

Atualmente eles estão despoluindo e revitalizando a lagoa,pois o cheiro e a poluição estava insuportável.Sei que vai levar um tempo para fazerem isso tudo e também tirarem o esgoto que nela desagua. Muito linda mas não limpa;

Esse lugar poderia ter sido melhor conservado pela população, caso fosse, seria muito bonito. O local tem lixo e está totalmente contaminado, seco, sujo e abandonado. Na orla tem um calçadão e as pessoas fazem caminhadas e corridas. $\mathrm{Na}$ paisagem deixa a desejar;

Um lugar muito bonito, mas infelizmente esta maltratada. As quadras de esporte estão todas depredadas e caminhar ali já se torna perigoso;

A Lagoa em si é péssima! Fedorenta e perigosa. Ao lado dela tem vários bares legais, por ficarem do lado contrário ao que o vento sopra o fedor não chega na maioria deles;

A vista é bem bonita, mas tu não consegues ficar muito tempo por causa da catinga. É altamente poluída, fede muito. No outro lado da lagoa está a vida noturna de São Luís. Muitos bares legais;

Apesar do bairro ser bom, com prédios de alto nível, a lagoa está exalando um cheiro muito ruim e as calçadas de seu perímetro estão mal conservadas.

Ratificando os aspectos negativos, Masulloet al. (2014, p. 05) afirmam que:

A área sofre, ainda, uma série de impactos ambientais, destacando-se os processos de eutrofização e colmatagem. Os esgotos são lançados in natura e acabam por contribuir para a multiplicação de algas cianofíceas que sufocam e matam o zooplâncton e os animais de maior porte cuja decomposição libera gases fétidos em grande intensidade. 
Com a urbanização da lagoa, o local foi favorecido com espaços para a prática de lazer e esporte por moradores e turistas, transformando-senuma referência, por representar a identidade local e também, onde estão inseridas as memórias sociais e a história da cidade.

O processo de urbanização que se procede na Laguna da Jansen é um dos graves
problemas ambientais que ocorrem na região, impulsionados pela ocupação
desordenada de sua orla e adjacências. Essa crescente demanda de construções, onde
se destacam vários prédios de grande porte que despejam uma grande quantidade de
esgotos domésticos nos corpos d'água e os resíduos sólidos jogados as suas
margens, deixando a laguna em progressivo estado de eutrofização, bem como
gerando diversos outros impactos subsequentes (Masulloet al., 2014, p. 04).

Portanto, preservar e conservar o ambiente natural são fundamentais para que a satisfação dos frequentadores e turistas seja positiva, pois, isso reflete na imagem do destino turístico (Gândara, 2008; Marujo, 2008) e também nos comentários que podem ser gerados em sites especializados de turismo como o Tripadvisor (Beal \& Strauss, 2008).Políticas públicas em nível estadual estão sendo realizadas quanto à balneabilidade das praias e despoluição de rios urbanos e da lagoa, que irão favorecer diretamente na qualidade de vida da população e turismo.

Serão investidos mais de R \$ 14 milhões nas obras de saneamento nesta etapa do 'Mais Saneamento'. Ao priorizar a meta de elevar o nível de tratamento de esgoto de São Luís, de 4\% para 70\% até o final de 2018, o Governo do Estado garante qualidade de vida, proteção ao meio ambiente e incentivo ao turismo no Maranhão (Maranhão, 2016).

Ações do atual governo do estado do Maranhão por intermédio da Companhia de Saneamento Ambiental do Maranhão (CAEMA) quanto à despoluição,promete retirar 27 pontos de lançamento de esgoto, no qual acreditam que:

Com estas ações conjuntas, em poucos meses nós vamos garantir condições bem melhores do ponto de vista de qualidade da água da Lagoa, viabilizando, assim, atividades que não são hoje praticadas, como esportes náuticos, e incrementando, também, ente outras coisas, o turismo nesta área (Maranhão, 2016).

Informações sobre a despoluição da Lagoa da Jansen publicada no site oficial do governo do Maranhão em dezembro de 2016, esclarecem que:

[...] dentro de alguns meses, será possível apreciar, na Lagoa e nas ruas que a circundam, mudanças resultantes deste trabalho que já interfere positivamente na vida dos moradores do entorno. Além da retirada de pontos de lançamento de esgotos clandestinos das margens da Lagoa - destinando-os para a elevatória instalada no local e a partir dela, enviando e tratando efluentes na ETEJaracati - há, também, o projeto de organização e implantação de redes em curso (Maranhão, 2016).

Mediante os comentários analisados acima, compreende-se que a tecnologiatem sido responsável pelo crescimento dos comentários online, o que possibilita uma maior 
conectividade do turista com o destino,m abrindo oportunidades diversas para o setor mediante os relatos das experiências vividas no destino (Buhalis\& Law, 2008;Hjalager, 2000). Ou seja, há uma disponibilidade de dados que podem ser processados e analisados, com fins para aperfeiçoar e direcionar (segmentar) produtos e serviços que atendam as exigências e necessidades reais dos visitantes, favorecendo também a uma gestão pública e privada a incrementar a infraestrutura e estratégias (Blanco, 2015). Site turísticos como o TripAdvisor possuem a capacidade de conectar e ampliar a comunicação entre os usuários. E vê-se que o turismo está cada vez mais afetado por esta mudança tecnológica, configurando uma nova forma de se pensar a atividade, assim como de compreensão (Filieri, 2015; Cuadra,Cañero,\&Agüera, 2014).

Esclarece-se que a reputação online tem crescido nos últimos anos e o monitoramento de mídias sociais é uma ferramenta de pesquisa para compreender as métricas válidas, a fim de compreender e analisar informações e dados postados para então desenvolver políticas públicas e planos de turismo (Gretzel\&Yoo, 2008; Cuadra,Cañero,\&Agüera, 2014;Santos et al., 2016).

\section{CONSIDERAÇÕES FINAIS}

O surgimento de novas ferramentas tem contribuído para a propagação de informações acerca dos destinos turísticos, ampliando o contato entre os turistas e visitantes, assim como moradores, como o caso de diversos sites de turismo, em específico o analisado TripAdvisor - que tornou-se uma referência para viajantes no mundo em busca de dicas e sugestões de passeios, hospedagem, restaurantes, bares, entre outros.

A reputação online é responsável na decisão da escolha ou não de um destino turístico, portanto, manter-se competitivo no mercado turístico, requer dos gestores ampliar a qualidade e a experiência para o visitante. Além disso, é o conjunto de opiniões dos consumidores que se realiza na internet sobre o produto, serviço e marca, portanto, este tornase um certificador, pois, estes atribuem veracidade e confiança sobre os comentários postados, além de promovem a divulgação e comunicação do atrativo na internet.

Quanto ao Parque Estadual da Lagoa da Jansen identificou-se que os comentários apontam principalmente para aspectos como poluição, sujeira e insegurança que de certo modo cria uma imagem negativa a mesma. Portanto, políticas públicastanto ambientais quanto turísticas devem promover a valorização deste território criando possibilidades de melhoria sanitária, conforme o governo do estado vem desenvolvendo com fins de devolver a população e turistas um local agradável para a prática de esportes e lazer. 
Por outro lado, identificou-se comentários positivos queratificaram o valor paisagístico do local, que é um dos principais produtos que o turismo utiliza na comercialização de um destino. Percebe-se neste sentido, queos comentários contribuem para que se entenda o território, contribuindo para que o turista obtenha cada vez mais informações acerca do atrativo e tenha experiência positiva.

Como forma de ampliar pesquisas científicas em torno do destino turístico São Luís, e aprofundar sobre a metodologia de reputação online (comentários), sugere-se que novas pesquisas sejam realizadas tratando dos aspectos da percepção dos visitantes não somente sobre este atrativo, mas de diversos outros existentes na cidade de São Luís, para que se tenha uma compreensão sobre como os usuários estão analisando os pontos turísticos da cidade em sites turísticos.

\section{REFERÊNCIAS}

Añaña, E. S., Anjos, F. A., \&Pereira, M. L. (2016). Imagem de destinos turísticos: avaliação à luz da teoria da experiência na economia baseada em serviços. Revista Brasileira de Pesquisa em Turismo. São Paulo, 10(2), 309-329.

Baggio, R., \&Del Chiappa, G. (2014). Real and virtual relationships in tourism digital ecosystems. Information Technology and Tourism, 14(1), 319.

Barich, H.,\&Kotler, P. (1991). A framework for marketing image management.Sloan Management Review, 32(2),94-104.

Beal, A., \&Strauss, J. (2008). Radically transparent: monitoring and managing reputations online. Sybex: Wiley.

Blanco, F. J.(2015). Libro blanco de los destinos turísticos inteligentes. Madrid: AcciónEmpresarial de LID Editorial.

Buhalis, D.(2000). Tourism and information technologies: Past, Present and Future. Tourism Recreation Research. 25(1), 41-58.

Buhalis, D., \&Law, R. (2008). Progress in information technology and tourism management: 20 years on and 10 years after the internet - The state of eTourism research. Tourism Management, 29(4), 609-623.

Brown, Millward. (2015). Visa global travel intentions study 2015. Executive Summary.

Cerqueira, R., \&Silva, T.(2011). Mensuração em mídias sociais: quarto âmbitos de métricas. In: Chamusca, M., \& Carvalhal, M.Comunicação e marketing digitais:conceitos,práticas, métricas e inovações. Salvador: VNI. Recuperado em 26, janeiro, 2016, http://www.slideshare.net/tarushijio/comunicacao-e-marketing-digitais-conceitos-praticasmetricas-e-inovacoes 
Cervo, A. L., \&Bervian, P. A. (2004). Metodologia científica.São Paulo:Pearson Pratice Hall.

Chagas, M. M., \& Dantas, A.V.S. (2008). Imagem de destinos turísticos e competitividade sustentável: um estudo de Natal sob a percepção do mercado Ibero-Holandês. RevistaDiversa, $1,231-250$.

Chun, R. (2005). Corporate reputation: meaning and measurement. International Journal of Management Reviews, V, 91-109.

Coelho, M. T. M.(2002). Avaliação da eficácia da lei de uso e ocupação do solo em São Luis: o caso da Lagoa da Jansen. 145f. Dissertação. (Mestrado em Desenvolvimento Urbano) Universidade Federal de Pernambuco, Recife.

Corrêa, C., \&Hansen, D. R. (2014). Qualidade de serviços em restaurantes de São Paulo premiados pelo TripAdvisor: análise do conteúdo gerado pelo usuário. Revista Hospitalidade, 271-290.

Cuadra, S. M., Morales, P. C.,\& Agüera, F. O. (2014) Reputación online, redes sociales y turismo. un estudio de caso en Andalucía. TuryDes. 7(16).

Creswell, J. W. (2007). Projeto de pesquisa: métodos qualitativo, quantitativo e misto. Porto Alegre: Artmed.

Dal Molin, E. D., \&Oliveira, J. P. (2008). Paisagem urbana e uso turístico: revitalização da rua Hercílio Luz em Itajaí (SC). Revista Eletrônica de Turismo Cultural. 2(1), 01-22.

Del Fresno, M. G. (2012). El consumidor social: Reputación online y social media. Barcelona: UOC.

Feger, J. E.,Souza Júnior, S. V., \&Gândara, J. M. G. (2016). Análise da reputação online do destino turístico Lapa (Paraná): uma aplicação do método TOURQUAL para análise da qualidade em serviços. Revista Iberoamericana de Turismo - RITUR, Penedo, 6(2), 138-156.

Figueiredo, M. Z. A., Chiari, B. M., \& Goulart, B. N. G. (2013).Discurso do Sujeito Coletivo: uma breve introdução à ferramenta de pesquisa qualiquantitativa. Distúrbios da Comunicação. 25(1), 129-136.

Filieri, R.. (2015). Why do travelerstrustTripAdvisor? Antecedents of trust towards consumergenerated media and its influence on recommendation adoption and word of mouth. Tourism Management. 51, 174-185.

Friedlander, R. J. (2012). Tendencias en la gestión de la reputación y las opiniones online de hoteles.Recuperado em 18, junho, 2018, de http://www.hosteltur.com/185350_tendenciasgestionreputacion-opiniones-online-hoteles.html.

Funsherpa. (2018). Online travel industry statistics. Recuperado em 12, janeiro, 2018 de https://skift.com/2012/07/30/infographic-how-tourists-use-the-internet-before-during-andafter-their-trip/ 
Gândara, J. M. G. (2008). A imagem dos destinos turísticos urbanos. Revista Eletrônica de Turismo Cultural.Número Especial, 1-22.

Gândara, J. M. G., Fraiz Brea, J. A., \&Manosso, F.(2013). Calidad de la experiencia en los hoteles termales de Galicia, Espana: un analisis a traves de la reputacion on line. Estudios yPerspectivas en Turismo (En Línea),22, 492-525.

GoPaul, M. (2014). Exploring customer satisfaction with the healthier food options available at fast-food outlets in South Africa. Dissertação de Mestrado. Pretoria: Universityof South Africa.

Google Maps. Localização da lagoa da jansen. Recuperado em 26, dezembro, 2016, de https://www.google.com.br/maps/place/Parque+Estadual+da+Lagoa+da+Jansen/@ $2.4960898,44.2971476,17 \mathrm{z} /$ data $=! 3 \mathrm{~m} 1 ! 4 \mathrm{~b} 1 ! 4 \mathrm{~m} 5 ! 3 \mathrm{~m} 4 ! 1 \mathrm{~s} 0 \times 7 \mathrm{f} 68 \mathrm{c} 30 \mathrm{e} 738 \mathrm{ca} 29: 0 x 1 \mathrm{~d} 1493 \mathrm{aea} 1 \mathrm{e}$ a22ea!8m2!3d-2.4960898!4d-44.2949589

Gretzel, U., \&Yoo, K. (2008): “Use and impact of online travelreviews". Information and Communication Technologies in Tourism, 35-46. Wien: Springer

G1Maranhão.(2012). Lagoa da Jansen apresenta problemas de infraestrutura. Recuperado em 16, abril, 2016, de http://g1.globo.com/ma/maranhao/noticia/2012/05/lagoa-da-jansenapresenta-problemas-de-infraestrutura.html

Hine, C. (2000). Virtual ethnography. London: Sage.

Hjalager, A. M. (2000). Tourism destinations and the concept of industrial districts. TourismandHospitalityResearch, 2(3), 199-213.

Imirante. (2014). Lixo na Lagoa da Jansen provoca mau cheiro e causa reclamações. Recuperado em 16, abril, 2016, dehttp://imirante.com/sao-luis/noticias/2014/04/15/lixo-nalagoa-da-jansen-provoca-mau-cheiro-e-causa-reclamacoes.shtml

Ivars-Baidal, J. A,Rodríguez-Sánchez, I. R., Vera-Rebollo, J. F., \&Acebal-Fernández, A. (2014). Nuevos enfoques em gestión turística: el programa de agrupaciones empresariales inovadorasem España. Boletín de la Asociación de Geógrafos Españoles. 66, 369-395.

Kozinets, R. V. (1998). On netnography: initial reflections on consumer research investigations of cyberculture. Evanston, Illinois.

Kurež, B.,\&Prevolšek, B. (2015). Influence of security threats on tourism destination development. Fakultetza sport iturizam, Novi Sad, TIMS, 9, 159-168.

Law, R., Qi, S., \&Buhalis, D. (2010). Progress in tourism management: a review of website evaluation in tourism research. Tourism Management. 31(3), 297-313.

Limberger, P. F., Anjos, F. A., Meira, J. V. S., \&Anjos, S. J. G. (2014). Satisfaction in hospitality on TripAdvisor.com: An analysis of the correlation between evaluation criteria and overall satisfaction. Tourism \& Management Studies, 10(1), 59-65.

Liu, Z.(2000). Internet tourism marketing:potential and constraints. Fourth International Conference Tourism in Southeast Asia \& Indo-China: Development, Marketing and Sustainability. The Scottish Hotel School. University of Strathclyde, UK. 
Main, H. (2001). The expansion of technology in small and medium hospitality enterprises with a focus on net technology. Information Technology \&Tourism, 4(3-4), 167-174.

Maranhão. Governo do Estado. (2015). Mais segurança para moradores e turistas na Lagoa da Jansen.Recuperado em 15, abril, 2016, de http://www.ma.gov.br/mais-seguranca-paramoradores-e-turistas-na-lagoa-da-jansen/

Maranhão. Governo do Estado. (2016). Mais segurança para moradores e turistas na Lagoa da Jansen.Recuperado em 25, maio, 2016, de http://www.ma.gov.br/retirada-de-pontos-deesgoto-garante-despoluicao-da-lagoa-da-jansen/

Maranhão. Governo do Estado (2012).Plano estratégico de turismo do estado do Maranhão: plano maior 2020-Relatório final. São Paulo: Chias Marketing.

María-Dolores, S. M.; García, J. J. B., \&Mellinas, J. P. (2012). Los hoteles de la región de Murcia ante las redes sociales y la reputación online. Revista de Análisis Turístico, 13, 1- 10.

Marujo, M. N. N. V. (2008). A internet como novo meio de comunicação para os destinos turísticos: o caso da Ilha da Madeira.Turismo em Análise. 19(1), 25-42.

Mason, J. C. (1993). Whatimage do youproject?.Management Review, 82(11), 10-16.

Masullo, Y. A. G., Ferreira, A. R. F., Santos, A. F., Soares, A. B. C., \&Ferreira, A. P. (2014). Análise multitemporal do uso e ocupação do solo na Lagoa da Jansen-MA. V.

Mendes-Filho, L., \& Carvalho, M. S. D. (2014). Factores que influyen en el uso del contenido generado por el usuário en internet. Un estúdio preliminar con viajeros brasileños. Estudios y Perspectivas en Turismo, 23, 607-625.

Minayo, M. C. S. (2008). O desafio do conhecimento. (11a ed.). São Paulo: Hucitec.

Middleton, V., \&Clark, J.R. (2012). Marketing in travel and tourism.(3a. ed.).Routledge, 512.

Montardo, S. (2009). Conteúdo gerado pelo consumidor: reflexões sobre sua apropriaçãopela comunicação corporativa. Revista Brasileira de Ciências da Comunicação. São Paulo, 33(2), 161-180.

Murphy, P., Pritchard, M. P., \& Smith, B. (2000). The destination product and its impact on traveler perceptions. Tourism Management, 21, 43-52.

Nghiêm-Phú, B. (2014). A review of destination image studies from 2008 to 2012.

EuropeanJournalofTourismResearch, 8, 35-65.

O Itaqui. (2016). Turistas aprovam policiamento realizado pela companhia de turismo independente. Recuperado em 10, janeiro, 2017, de

http://www.oitaqui.com.br/cidade/2016/07/19/turistas-aprovam-policiamento-realizado-pelacompanhia-de-turismo-independente.html

Pereira, C. S. (2005). Imagine Yourself Set Down... In Front OfYour PC: a etnografia e o desafio metodológico da netnografia. Revista de Antropologia, (6), 1- 21. 
Pechlaner, H., Rienzner, H., Matzler, K., \&Osti, L. (2002). Response Attitudes and Behavior of Hotel Industry to Electronic info Requests. In K.W. Wöber, A.J. Frew, \& M. Hitz (Eds). Information and Communication Technologies in Tourism, 177-196, Springer-Verlag Wien.

Pike, S. (2008). Destinaton Marketing. Oxford (UK): Elsevier Inc.

Pinto, R. A. (2012). Formação das imagens no turismo: itinerário teórico e proposta de um modelo operacional. TurismoemAnálise. 23(3),552-574.

Prayag, G. (2008). Image, Satisfaction and Loyalty: The Case of Cape Town. Journal of Tourism and Hospitality Research. 19(2), 205-224.

Quiroga, R. M., Mondo, T. S., \&Castro Júnior, D. F. L.(2014). Reputação online como instrumento para melhoria de serviços: um estudo na hotelaria de Garopaba e Imbituba Santa Catarina. Revista de Turismo Contemporâneo, 2(1), 95-112.

Reino, S. S., A.,Lamsfus, C., \&Azua-Sorzabal, A.(2012). A new hotel online reputation framework for ontology learning development. Helsingborg, Sweden.

Sakata, F. G. (2011). Paisagismo urbano:requalificação e criação de imagens. São Paulo: Editora da Universidade de São Paulo - EDUSP.

Santos, S. R., Hardt, L. P. A., Hardt, C., \&Santos, P. C. (2013). Transformações da paisagem urbana do bairro Renascença II em São Luís (MA) sob a ótica dos moradores. In: Mattos Júnior, J. S. de; Santos, P. C. dos. (Org.) Desenvolvimento socioespacial:novos olhares. São Luís: EDUEMA, 201-220.

Santos, S. R. (2015).Paisagem solidária: indicadores de sustentabilidade urbana em área turística funcional do centro histórico de São Luís, Maranhão. Tese de doutorado em Gestão Urbana, Pontifícia Universidade Católica do Paraná, Curitiba, PR, Brasil.

Santos, S. R., Souza Neto, V. R., Pereira, L. R. S., Gândara, J. M. G.,\&Silva, S.R. X. (2016). Destino turístico inteligente: acessibilidade no centro histórico de São Luís - Maranhão, um estudo sobre a reputação online no TripAdvisor. Marketing \&TourismReview. 1(2), 1-27.

Santos, S. R. (2016).Imagem da lagoa da jansen em São Luís.

São Luís. (2014). Secretaria Municipal de Turismo de São Luís. Pesquisa de turismo receptivo /festa junina: relatório. São Luís, junho.

Segittur. (2013). Destinos turísticos inteligentes. Recuperado em 23, setembro, 2016, http://www.segittur.es/opencms/export/sites/segitur/.content/galerias/descarga s/documentos/Presentacin-Destinos-Tursticos-Inteligentes.pdf

Segittur. (2015). Smartdestination: informe destinos turísticos inteligentes: construyendoel futuro. Madrid.

Soares, Z. (2012). Maranhão realiza virada pela sustentabilidade. Recuperado em 25, janeiro, 2016, de http://www.blogsoestado.com/zecasoares/2012/12/14/maranhao-realizavirada-pela-sustentabilidade/ 
Solomon, M. (2011). O comportamento do consumidor:comprando, possuindo e sendo. Porto Alegre: Bookman.

Steinke, V. A., Reis Junior, D. F., \& Costa, E. B. (Orgs.). (2014). Geografia e fotografia:apontamentos teóricos e metodológicos. Brasília: LAGIM-UNB.

Tasci, A. D. A., \&Gartner, W. C. (2007). Destination image and its functional relationships. JournalofTravelResearch. 45(4), 413-425.

Teixeira, O.(2016). Entrevista concedida no portal SuaCidade.com-Lagoa da Jansen sofre os efeitos do abandono. Recuperado em 15, abril, 2016,

http://www.suacidade.com/20121219/lagoa-da-jansen-sofre-os-efeitos-do-abandono

Tripadvisor. (2013). Trip Barometer by TripAdvisor-Winter 2012/2013. Recuperado em 25, agosto, 2016, de

http://www.tripadvisortripbarometer.com/download/Global\%20Reports/TripBarometer\%20by \%20TripAdvisor\%20-\%20Global\%20Report\%20-\%20USA.pdf

Tripadvisor. (2013). Lagoa da Jansen. Recuperado em 20, janeiro, 2016, de https://www.tripadvisor.com.br/Attraction_Review-g673267-d2391623-ReviewsLagoa_da_Jansen-Sao_Luis_State_of_Maranhao.html

Yázigi, E. (2002).Turismo e paisagem. São Paulo: Contexto.

SANTOS, S., \&GÂNDARA, J. M. G. (2018). Do que falam os turistas sobre o parque estadual lagoa da Jansen em São Luís/Maranhão no Tripadvisor?. Revista de Turismo Contemporâneo, 6(2), 291-314. 